\title{
A Formação Inicial do Professor na Modalidade a Distância para o Uso das Tecnologias Digitais no Ensino de Matemática: O Caso de uma Disciplina de Prática de Ensino
} (The Initial Formation Teacher in the Distance Mode for the Use of Digital Technologies in the Teaching of Mathematics: The Case of a Disciplinary Teaching Practice)

\section{MARÍLIA ZABEL ${ }^{1}$ e ANA PAULA DOS SANTOS MALHEIROS ${ }^{2}$}

1 Universidade Estadual Paulista "Júlio de Mesquita Filho", campus de Rio Claro (zabel.marilia@gmail.com)

${ }^{2}$ Universidade Estadual Paulista "Júlio de Mesquita Filho", campus de São José do Rio (malheiros.anapaula@gmail.com)

\begin{abstract}
Resumo. Este artigo tem como objetivo discutir de que modo uma disciplina de Prática de Ensino contribui para a formação do professor de Matemática em relação ao uso das tecnologias digitais na Educação Básica. A partir de uma abordagem qualitativa, utilizamos como procedimentos metodológicos o acompanhamento da disciplina e entrevistas realizadas com alguns licenciandos e com o professor. Para a compreensão dos dados, nos apoiamos em Bovo (2004), que elenca alguns conhecimentos necessários aos professores para o uso das tecnologias digitais, e outros autores como Ponte et al. (2003), Perrenoud (2000) e Costa et al. (2012), que apontam competências relacionadas a esses conhecimentos. A partir disso, identificamos que a disciplina promoveu o desenvolvimento de competências e conhecimentos relacionados ao uso de tecnologias digitais nos processos de ensino e aprendizagem de Matemática, sendo que os futuros professores puderam articular conhecimentos teóricos e práticos durante a disciplina, além de discutirem sobre as possibilidades dessas tecnologias no contexto escolar.

Abstract. This article aims to discuss how a Teaching Practice discipline contributes to the formation of mathematics teachers regarding the use of digital technologies in basic education. From a qualitative approach, we use as instruments monitoring the discipline and interviews with some undergraduates and the teacher. To understand the data, we based on Bovo (2004), which lists some knowledges needed by the teachers in the use of digital technologies, and other authors such as Ponte et al. (2003), Perrenoud (2000) and Costa et al (2012), pointing skills related thereto. Thus, we identified that the discipline promoted the development of skills and knowledge related to the use of digital technologies in the teaching and learning of Mathematics, and the future teachers could articulate theoretical and practical knowledge during the discipline besides discussed about the possibilities of these technologies in the school context.
\end{abstract}

Palavras-chave: educação a distância, formação de professores, licenciatura em matemática, tecnologias digitais

Keywords: distance education, teacher training, degree in mathematics, digital technologies

\section{Introdução}

Este artigo apresenta algumas reflexões realizadas a partir do desenvolvimento de uma pesquisa de Mestrado (ZABEL, 2014) que buscou compreender como acontece a formação de professores em relação à utilização das tecnologias digitais para o ensino de Matemática, a partir da disciplina de Prática de Ensino do curso de Licenciatura em Matemática a distância da Universidade Federal de Ouro Preto (UFOP).

Tal pesquisa foi desenvolvida a partir da nossa inquietação sobre a formação dos professores de Matemática, em especial os da modalidade a distância, para o uso das tecnologias digitais no contexto escolar. Isso porque, quando pensamos num curso 
ofertado na modalidade a distância, pressupomos que as tecnologias digitais já fazem parte dos processos de ensino e aprendizagem, ao longo de todo o período de formação. Então, desejávamos entender como uma disciplina que trata da utilização das tecnologias digitais no ensino e na aprendizagem de Matemática ocorre, sendo que ela deve ser ministrada também por meio delas.

Diante disso, neste artigo apresentamos um dos vieses tomados pela nossa pesquisa. Nesse viés buscamos identificar, por meio da literatura, as necessidades dos professores de Matemática para integrarem as tecnologias digitais no ensino dessa disciplina, articulando os resultados dessa busca com os momentos vivenciados nela. Assim, o objetivo principal deste artigo é discutir de que modo uma disciplina de Prática de Ensino, ofertada na modalidade a distância, contribui para a formação do professor de Matemática em relação às suas necessidades para o uso das tecnologias digitais nos processos de ensino e aprendizagem.

Para isso, primeiramente vamos apresentar uma discussão teórica relacionada à formação do professor para o uso das tecnologias digitais. Em seguida, descrevemos o cenário no qual nossa investigação aconteceu, bem como a metodologia de pesquisa utilizada. A partir disso, vamos verificar como essa disciplina contribuiu para a formação desses licenciandos, considerando os momentos registrados durante a disciplina e as entrevistas realizadas com os mesmos.

\section{Conhecimentos e competências para o uso das tecnologias digitais nas aulas de matemática}

No que diz respeito à formação de professores, o Conselho Nacional da Educação estabeleceu Diretrizes Curriculares Nacionais para a Formação de Professores da Educação Básica (BRASIL, 2002). Destacamos, nesse documento, o Artigo 2º que se refere à organização curricular de cada instituição. Ele sugere que essa deverá observar formas de orientação inerentes ao desenvolvimento da atividade docente, entre as quais, o preparo para o uso das tecnologias digitais e de metodologias, estratégias e materiais de apoio inovadores.

Em relação à Licenciatura em Matemática, as Diretrizes Curriculares Nacionais específicas desse curso (BRASIL, 2001) reforçam que o licenciando deve adquirir familiaridade com o uso do computador como instrumento de trabalho, incentivando sua utilização para o ensino de Matemática. Além disso, evidenciam a importância da 
familiarização do licenciando, ao longo do curso, com outras tecnologias ${ }^{1}$ que possam contribuir para esse ensino.

Assim, é notório que a legislação prevê que os cursos de formação inicial de professores de Matemática preparem seus licenciandos para utilização das tecnologias digitais na sala de aula. Entendemos, no entanto, que seria inviável determinar o que explicitamente cada curso deve oferecer, considerando as características regionais e culturais do nosso país, além das diferentes possibilidades, pensando nas diversas áreas do conhecimento.

Porém, acreditamos ser possível elencar alguns elementos básicos que possam vir a contribuir para o preparo do professor em relação ao uso das tecnologias digitais, com base em estudos já realizados. Nesse sentido, Bovo (2004) elenca e descreve três conhecimentos que considera necessários ao professor: conhecimentos técnicos sobre os softwares, conhecimentos sobre as possibilidades e diferentes abordagens do uso pedagógico do computador para o ensino e a aprendizagem da Matemática e conhecimentos de como organizar uma atividade e de como integrá-la ao currículo. Evidenciamos que, embora já tenham se passado dez anos da publicação do trabalho de Bovo (2004), as ideias apontadas pela autora em relação a formação dos professores para o uso das tecnologias digitais ainda são atuais e corroboram as perspectivas de outros autores que mencionaremos neste artigo.

Destacamos, ainda, que os conhecimentos elencados em Bovo (2004) vão ao encontro das ideias apontadas por Ponte et al. (2003), que defendem que os professores precisam saber como utilizar os novos equipamentos e softwares, identificando seus potenciais, pontos fortes e fracos. Para isso, esses autores consideram que os cursos de formação inicial de professores devem dar atenção ao desenvolvimento de algumas competências no que se refere ao uso das tecnologias digitais para processo de ensino e aprendizagem, sendo elas:

- Usar softwares utilitários;

- Usar e avaliar softwares educativos;

- Integrar as tecnologias em situações de ensino e aprendizagem;

- Enquadrar as tecnologias num novo paradigma do conhecimento e da aprendizagem;

- Conhecer as implicações sociais e éticas das tecnologias.

\footnotetext{
${ }^{1}$ Podemos considerar outras tecnologias, por exemplo, as calculadoras e os tablets.
} 
No que diz respeito à ideia de competências, Santos e Brito (2011), ao analisarem documentos legais relacionados à formação do professor, evidenciaram trechos que remetem a termos do discurso taylorista, fordista e toyotista ${ }^{2}$, identificando que o termo competência pode estar sendo utilizado na formação do professor, tendendo a visualizar seu o trabalho como uma mercadoria. Consideramos que esses estudos são importantes para refletirmos sobre o trabalho docente, porém, como já mencionado, neste artigo buscamos identificar o que é considerado necessário para que um professor possa utilizar as tecnologias e esses autores se apropriam do termo competência para descrever tal necessidade. Ainda, reiteramos a opinião das autoras no sentido de que não é possível saber o quanto os autores das legislações sobre formação de professores, e ampliamos para os demais autores citados neste texto, tinham consciência da aproximação de termos como competência com os modelos de organização do trabalho.

Desse modo, em um sentido mais amplo, Philippe Perrenoud elencou as "Dez Novas Competências para Ensinar", sendo que estas também deveriam orientar as formações iniciais e continuadas. A noção de competência assumida por Perrenoud (2000) está relacionada à capacidade de mobilizar diversos recursos $\operatorname{cognitivos}^{3}$ para enfrentar determinada situação. Ou seja, a capacidade de colocar em prática um conhecimento específico. Assim, para cada uma das dez competências determinadas, o autor associa outras mais específicas, que podem ser vistas como seus componentes principais.

Umas das competências elencadas por Perrenoud (2000) é "Utilizar Novas Tecnologias". Para ele, as tecnologias digitais transformam as maneiras de se trabalhar, decidir e pensar, assim, seria indefensável não falar a respeito delas num curso de formação inicial ou continuada. Segundo o autor, os componentes principais relacionados a essa competência são:

- Utilizar editor de texto;

\footnotetext{
${ }^{2} \mathrm{O}$ modelo taylorista foi um modelo de organização de trabalho que "[...] defendia a cisão entre o pensar e o agir, ou entre o planejar e o executar. Uma minoria de trabalhadores era destinada a elaborar metodicamente as tarefas e outros a executá-las" (SANTOS; BRITO, 2011, p. 57). Já o modelo fordista pode ser considerado uma ampliação do taylorista, no qual se prioriza também a criação de um ambiente tomado pela tecnologia, que viabilize a intensificação e o maior aproveitamento da matéria-prima, bem como da exploração da mão de obra. Por fim, o modelo toyotista é uma nova organização de trabalho na qual se explicita a necessidade do uso de toda a subjetividade dos trabalhadores. Nessa organização, o trabalhador pode e deve [re] elaborar as normas postas, fazendo uma união entre teoria e prática se isso convier ao desempenho das atividades de trabalho (SANTOS; BRITO, 2011).

${ }^{3}$ Recursos cognitivos, para o autor, são os saberes, as capacidades, as informações.
} 
- Explorar as potencialidades didáticas dos programas em relação aos objetivos do ensino;

- Comunicar-se à distância por meio da telemática;

- Utilizar as ferramentas multimídia no ensino.

Nessa perspectiva, Perrenoud (2000) defende que para o professor explorar as potencialidades didáticas dos programas educacionais, não é necessário que se torne especialista em informática ou programação, pois muitos softwares educacionais não exigem isso. $\mathrm{O}$ autor considera que a facilidade de trabalhar com os softwares pode não garantir uma correta aplicação para fins didáticos, mas de certa forma, contribui para que isso se torne possível. Nesse sentido, os Parâmetros Curriculares Nacionais (BRASIL, 1998) apontam que é imprescindível que o professor saiba escolher os softwares educacionais em função dos objetivos que pretende atingir. Acreditamos que o mesmo vale para as demais tecnologias digitais.

Mais recentemente, Costa et al. (2012) elencaram dez competências que consideram essenciais para a utilização adequada e consciente das tecnologias na educação. Para esses autores, a noção de competência está relacionada ao "desenvolvimento integrado de capacidades e atitudes que viabilizam a utilização do conhecimento em situações diversas" (COSTA et al., 2012, p. 51). Nesse sentido, para eles, é necessário aos professores:

- Ter conhecimento atualizado sobre os recursos tecnológicos e seu potencial de uso educativo;

- Acompanhar o desenvolvimento tecnológico no que implica a sua responsabilidade profissional;

- Executar operações com hardware e software (usar e instalar programas, resolver problemas comuns com o computador e periféricos, criar e gerir documentos e pastas); observar regras de segurança no respeito pela legalidade e princípios éticos, etc.;

- Organizar e sistematizar a informação em formato digital (pesquisar, selecionar e avaliar a informação em função de objetivos concretos);

- Executar operações com programas ou sistemas de informação online e/ou off-line (aceder a Internet, pesquisar em banco de dados ou diretórios, aceder obras de referências, etc.); 
- Comunicar-se com os outros, individualmente ou em grupos, de forma síncrona ou assíncrona através de ferramentas digitais específicas;

- Elaborar documentos em formato digital com diferentes finalidades e para diferentes públicos, em contextos diversificados;

- Conhecer e utilizar ferramentas digitais como suporte de processos de avaliação e/ou investigação;

- Utilizar o potencial dos recursos digitais na promoção do seu próprio desenvolvimento profissional numa perspectiva de aprendizagem ao longo da vida;

- Compreender vantagens e desvantagens do uso das tecnologias digitais no processo educativo e o seu potencial transformador no modo como se aprende (COSTA et al., 2012).

Ao pensar nas competências que foram mencionadas até então, precisamos entender que cada autor as elencou de acordo com sua perspectiva de trabalho e o que assumem como competência e também como tecnologia. Porém, podemos perceber que muitas das competências mencionadas se assemelham e, além disso, corroboram com os conhecimentos apontados por Bovo (2004).

Os conhecimentos técnicos (BOVO, 2004) estão relacionados ao domínio que os professores deveriam ter sobre os softwares que utilizarem em sala de aula, no sentido de conhecer e estar familiarizados com as ferramentas disponíveis neles, além dos domínios sobre o próprio computador, por exemplo. Assim, as competências de como utilizar softwares utilitários, usar editor de texto, executar operações com hardware e software e executar operações com programas e sistemas de informação online e/ou offline estão relacionadas tanto entre si, quanto com os conhecimentos técnicos.

Entendemos que os professores precisam desenvolver essas habilidades. No entanto, acreditamos ser preciso tomar cuidado para que as iniciativas propostas num curso de formação, que propiciam o acesso às tecnologias digitais, o domínio dos recursos tecnológicos e sua utilização para o entretenimento e busca de informações, não fiquem centradas apenas "[...] no domínio instrumental, que traz poucas contribuições para o desenvolvimento de novas aprendizagens" (ALMEIDA, 2007, p. $8)$.

Assim, entendemos que também é preciso que os cursos de formação de professores desenvolvam conhecimentos sobre as abordagens das tecnologias digitais no ensino de Matemática e organização de atividades (BOVO, 2004), que se referem à 
forma como o professor vê o uso das tecnologias digitais na sala de aula, buscando relacioná-lo aos processos de ensino e aprendizagem. Algumas das competências mencionadas que corroboram esses conhecimentos e que podem estar sendo desenvolvidas no futuro professor são: integrar as tecnologias digitais em situações de ensino-aprendizagem, explorar suas potencialidades didáticas e compreender vantagens e constrangimentos do uso das tecnologias digitais no processo educativo.

A partir da perspectiva apresentada, consideramos que todos os conhecimentos e competências aqui citados contribuem para que o professor sinta-se preparado para utilizar as tecnologias digitais na sala de aula. Para isso, entendemos ser fundamental que, num curso de formação inicial, os licenciandos tenham contato com as tecnologias digitais a partir de disciplinas que visem o desenvolvimento desses conhecimentos, a fim de formar professores preparados para o seu uso no ensino de Matemática. A seguir, vamos identificar como a disciplina acompanhada possibilitou a produção de tais conhecimentos e competências.

\section{O cenário de investigação e aspectos metodológicos}

Tivemos como cenário de investigação para nossa pesquisa, a disciplina Prática de Ensino, com ênfase na formação para o uso de tecnologias no ensino de Matemática, ofertada na modalidade de ensino a distância do curso de Licenciatura em Matemática da UFOP. A ementa da disciplina mencionada é constituída por:

\footnotetext{
O contributo das Tecnologias da Informação e Comunicação para o ensino e aprendizagem da Matemática. Informática e Educação Matemática. Programas matemáticos: Vantagens e desvantagens. Alguns programas matemáticos e suas aplicações às aulas de Matemática. A internet e seu potencial para a pesquisa e ensino-aprendizagem (UFOP, 2009, p.23).
}

Por se tratar de uma disciplina ofertada na modalidade a distância, sua dinâmica foi um pouco diferente. Semanalmente, o professor disponibilizava o material de estudo e abria um fórum para discussão e dúvidas, no ambiente virtual da disciplina, sendo que nesse fórum, participavam os alunos de todos os polos, o tutor a distância e o professor.

Ao total, foram 16 semanas de aulas, sendo divididas da seguinte forma: as duas primeiras semanas da disciplina foram destinadas a discussões de textos que abordavam temas como Educação Matemática, tecnologias e o uso das tecnologias na educação (BORBA, 2002; BASTOS, 2005; MENDES, 2008). Nas semanas seguintes, as atividades disponibilizadas no ambiente virtual estavam relacionadas às construções dos 
Podcasts $^{4}$ e Screencasts ${ }^{5}$. Posterior a esse momento, o professor apresentou a perspectiva das tarefas exploratório-investigativas. Para isso, disponibilizou um texto (PONTE, 2003a) e quatro exemplos de tarefas investigativas que fazem uso de recursos tecnológicos. Por fim, pensando no compartilhamento das atividades construídas pelos licenciandos, o professor propôs a criação de um blog e uma conta em um servidor para disponibilizar materiais produzidos na Internet.

Desse modo, os dados produzidos para a pesquisa são oriundos basicamente de dois procedimentos: o acompanhamento da disciplina e entrevistas. Para o acompanhamento da disciplina, utilizamos um perfil de pesquisador e tivemos acesso a todo o ambiente virtual. Já as entrevistas foram realizadas ao final da disciplina e procuramos por meio delas, compreender alguns momentos vivenciados ao longo da mesma.

Assim, destacamos que utilizamos a metodologia da pesquisa qualitativa, pois, de acordo com D'Ambrosio (2004), ela tem como foco entender e interpretar dados e discursos, mesmo quando envolve grupos de participantes. Além disso, na "[...] pesquisa qualitativa a preocupação do pesquisador não é com a representatividade numérica do grupo pesquisado, mas com o aprofundamento da compreensão de um grupo social, de uma organização, de uma instituição, etc.” (GOLDENBERG, 2003, p. 14).

\section{O desenvolvimento dos conhecimentos para o uso das tecnologias digitais}

Mencionamos anteriormente alguns conhecimentos apontados por diversos autores como sendo necessários para o uso das tecnologias digitais na sala de aula. Evidenciamos, também, que acreditamos que esses conhecimentos devem ser desenvolvidos já na formação inicial do professor. Assim, considerando que a disciplina acompanhada é de um curso de formação inicial de professores e que trata especialmente do uso das tecnologias no ensino, acreditamos ser possível identificar a produção de alguns conhecimentos nos licenciandos, a partir de um olhar para as atividades propostas e desenvolvidas ao longo da disciplina.

Nas primeiras atividades, o professor propôs a discussão de textos que tratavam de temas relacionados com Educação Matemática, tecnologias e o uso de tecnologias no

\footnotetext{
${ }^{4}$ Arquivos de áudio no formato MP3 que são disponibilizados na Internet.

${ }^{5}$ Um screencast é um vídeo produzido a partir da captura ou gravação digital da tela do computador, sendo possível gravar o áudio do utilizador.
} 
ensino de Matemática, sendo abertos fóruns para essas discussões. Esses fóruns tiveram alta participação dos licenciandos que, baseados nos textos, postaram suas opiniões sobre esses temas. Percebemos, por meio das mensagens postadas, que os licenciandos reconhecem a importância de que o professor precisa produzir conhecimentos para utilizar as tecnologias de maneira a proporcionar um ensino que não busque apenas a inserção das tecnologias.

Precisamos pensar em como vamos conciliar o avanço tecnológico com o nosso propósito de ir para sala de aula e ministrar aulas de matemática. Concordo plenamente que a tecnologia auxilia e "facilita" a vida dos professores e dos alunos [...] Mas o que interessa pra nós, futuros professores de matemática, é descobrir e aproveitar de maneira saudável e prazerosa como os recursos tecnológicos serão nossos aliados na difícil atividade de ensinar matemática. [Mensagem postada no fórum por Sérgio em 24/06/2013]

[...] é necessário rever a forma como as tecnologias são incorporadas na formação do professor. Não basta ser usuário de um programa, o professor precisa aprender a usar as tecnologias como novo ambiente de aprendizagem e de construção de conhecimento. [Mensagem postada no fórum por Ana em 02/07/2013]

Nessas falas, podemos verificar que, de fato, os licenciandos reconhecem o papel da formação do professor para produzir conhecimentos relacionados ao uso das tecnologias para o ensino de Matemática. É evidente também que eles desejam que esse uso seja efetivado de forma a garantir um ensino com mais qualidade, considerando a aprendizagem dos alunos. Desse modo, acreditamos que além das experiências pessoais de cada um, os textos disponíveis para leitura e discussão, que, de certa forma, tratam desses aspectos, podem ter contribuído para os licenciandos apresentarem essa visão. Assim, entendemos que a leitura dos textos possibilitou aos licenciandos um conhecimento teórico sobre as tecnologias e seu uso na sala de aula. Quando os questionamos, durante a entrevista, sobre o papel dos textos para sua formação, as ideias apresentadas corroboraram nossa compreensão sobre essa atividade, como podemos evidenciar nas falas a seguir:

Extrema importância, pois com base nos textos disponibilizados pelo professor eu me preparo para lidar com as tecnologias em sala de aula e meu leque de possibilidades a serem trabalhadas com os alunos se torna extenso... [Trecho da entrevista realizada com Luiza em 18/09/2013]

Se o aluno [futuro professor] aprender apenas técnicas de ensino, sem o embasamento teórico, tem grandes chances de "não saber o que está fazendo", e acabar não sendo um bom profissional. [Trecho da entrevista realizada com Maiara em 19/09/2013]

Assim, podemos notar que eles reconhecem que o conhecimento teórico, proveniente da leitura de textos, é importante para o seu desenvolvimento profissional e 
para se sentirem aptos para o uso das tecnologias na sala de aula. Além disso, entendemos que essas leituras, dão subsídios para as reflexões sobre os momentos que se produz com tecnologia, possibilitando que o desenvolvimento de competências ocorra por meio de uma sistematização teórica articulada com o fazer (BRASIL, 2001).

Passando da abordagem teórica para um viés mais prático, durante seis semanas foram discutidos e construídos podcasts e screencasts, com foco na produção de material didático. Entendemos que para a produção de tais recursos é fundamental que haja certo domínio sobre alguns softwares e ferramentas. No entanto, percebemos que os licenciandos apresentaram, principalmente no início, muitas dificuldades para utilizálos, como podemos evidenciar nos registros que foram postados nos fóruns:

\begin{abstract}
Acho bastante interessante o uso de recursos tecnológicos, mas isso precisa ser bastante criterioso. Percebi por parte dos alunos que vários tiveram dificuldade em instalar o audacity ${ }^{6}$, na parte do exportar para MP3 ${ }^{7}$. Só consegui instalar na quinta-feira com a ajuda de outra pessoa. Mas creio eu que isso tem haver com pouco habito nosso em mexer com programas. Fiz um arquivo simples pq ainda estou apanhando muito desse programa. [Mensagem postada no fórum por Sérgio em 04/07/2013]

Boa Noite Professor, sobre a criação do screencast, fiz alguns vídeos para meus alunos de informática, e salvei em dois formatos tanto em flash como AVI para vídeo. Como faço para carregar este arquivo em flash, em formato de página de internet? [Mensagem postada no fórum por Bárbara em $11 / 08 / 2013]$

Olá professor, boa tarde, fiz a gravação no BlueBerry, porém na hora de salvar o arquivo em swf não consigo salvar. Antes eu estava fazendo o teste tudo estava certo, agora estou tentando e não dá certo será que eu desativei alguma coisa no programa? Preciso fazer outro download? Abraço. [Mensagem postada no fórum por Rosana em 19/08/2013]
\end{abstract}

Essas mensagens revelam algumas dificuldades dos licenciandos que foram postadas nos fóruns, que se relacionam, basicamente, a como fazer o download de um programa, ao uso de algumas ferramentas de programas específicos, a como salvar o arquivo em determinado formato. Assim, durante as semanas de produção dos recursos de áudio e vídeo, houve bastante participação dos licenciandos nos fóruns de discussão, nos quais os alunos postavam suas dúvidas e recebiam um feedback do professor, que tentava esclarece-las.

Mesmo que, na maioria das vezes, os alunos não dessem um retorno no fórum, mencionando se conseguiram ou não solucionar os problemas encontrados, podemos considerar que houve a produção de alguns conhecimentos técnicos, visto que os mesmos postaram suas atividades realizadas (o que pode implicar que suas dúvidas

6 Software gratuito que grava e edita áudios no computador. Disponível para download em: $<$ http://audacity.sourceforge.net/?lang=pt-BR> Acesso em: 25 de maio de 2014.

${ }^{7}$ Tipo de leitor de arquivos em formato de áudio. 
foram solucionadas). Assim, inferimos que a produção desses recursos possibilitou que os licenciandos executassem operações com hardware e softwares e operações com programas e utilizassem ferramentas digitais, visto que foram atividades necessárias para a construção dos áudios e vídeos.

Destacamos que, durante as semanas que foram destinadas a produção desses recursos, não houve, nos fóruns, momentos de discussões sobre o uso dos podcast e screencast no ensino de Matemática. Pensando nisso, questionamos os licenciandos, durante as entrevistas, sobre as possibilidades desse uso, sendo que eles destacaram algumas, como podemos ver nas falas a seguir:

[...] acredito que um screencast pode ser um complemento para as aulas em sala de aula [...] [Trecho da entrevista realizada com Alexandre em 19/09/2013]

[...] eles [podcast e screencast] podem auxiliar na correção de exercícios, explicação e desenvolvimento de matérias. [Trecho da entrevista realizada com Carlos em 28/09/2013]

[...] pretendo utilizar esses recursos a partir do início do próximo ano letivo para deixar recados e breves explicações em uma espécie de blog que será voltado aos meus alunos. [Trecho da entrevista realizada com Angela em $18 / 09 / 2013]$

[...] acho que o screencast, o podcast, o blog e tudo mais ajudam na interação do aluno com o professor, a talvez conseguir uma ligação entre o professor e $\mathrm{o}$ aluno que não seja aquela antiga que se resumia em respeito e nem a atual que me parece ser de afastamento. [Trecho da entrevista realizada com Anderson em 03/10/2013]

Nessas falas, podemos evidenciar que o uso dos podcast e screencast está sendo visto numa perspectiva de apoio ou complemento a aula na modalidade presencial. Essa perspectiva vai ao encontro do que Maltempi e Malheiros (2010) chamam de educação contemporânea, na qual, as tecnologias são utilizadas para ensinar as pessoas, sendo que esse ensino ocorre por meio de atividades presenciais e a distância.

É interessante perceber que, mesmo não havendo um momento de discussão entre os licenciandos e o professor durante a disciplina, eles refletiram sobre suas produções, visualizando possibilidades para o seu uso no contexto educacional. Desse modo, podemos destacar que a atividade de construção desses recursos possibilitou que o conhecimento relacionado ao uso pedagógico do computador para o ensino e aprendizagem de Matemática fosse produzido, a medida que os licenciandos refletiram sobre suas produções e vislumbraram possibilidades para utilização desses recursos na sala de aula.

Além de uma reflexão individual, podemos considerar também o fato de os alunos estarem em um curso a distância em que muitos professores utilizam esses recursos em 
suas disciplinas. Nesse sentido, acreditamos que isso corrobora Maltempi e Malheiros (2010) que acreditam que a educação matemática a distância reflete, atualmente, na educação matemática presencial, no sentido de que as experiências, crenças e modelos de ensino desse último são reproduzidas no primeiro.

Finalizada a produção dos recursos de áudio e vídeo, outro viés foi abordado na disciplina. O professor, na $11^{\mathrm{a}}$ semana de aula, apresentou aos alunos a perspectiva da Investigação Matemática ${ }^{8}$. O objetivo dessa proposta era relacionar o uso das tecnologias digitais com essa abordagem metodológica, ou seja, propor atividades de Investigação Matemática que utilizasse algum recurso tecnológico. Para isso, o professor disponibilizou um texto (PONTE, 2003b) que apresenta e discute sobre as investigações e quatro exemplos de atividades investigativas.

Num dos exemplos proposto pelo professor, a temática explorada era a condição de existência de um triângulo. Nessa atividade, a proposta é que por meio da manipulação de segmentos de retas com diferentes tamanhos, obtenham-se conjecturas com as quais é possível perceber que existe uma condição para os triângulos existirem. O diferencial da atividade é que além de ser uma tarefa exploratório-investigativa, ela é realizada manipulando um software. Sobre esse exemplo, alguns comentários dos alunos postados no fórum foram:

Eu teria adorado fazer essa investigação quando criança! Nunca esqueceria a
relação entre o tamanho dos lados do triângulo! E o mesmo material pode ser
utilizado para provar que a hipotenusa é sempre o maior lado do triângulo
retângulo. Adicionando um esquadro, podemos provar vários resultados
sobre ângulos de triângulos (como são iguais na base do isósceles, por
exemplo). E muitos outros resultados, com certeza! [Mensagem postada no
fórum por Maiara em 21/08/2013]
Numa perspectiva inovadora esta aula utiliza de recursos metodológicos
simples mas com alto poder de uma aprendizagem satisfatória, o lúdico
trabalhado de forma concreta contribui para o desenvolvimento do saber.
Com as metodologias aqui ensinadas me vejo como uma profissional cada
vez mais qualificada. [Mensagem postada no fórum por Roberta em
$27 / 08 / 2013$ ]
Uma boa maneira de mostrar aos alunos que 3 retas nem sempre formam um
triângulo. [Mensagem postada no fórum por Jéssica em 25/08/2013]

${ }^{8}$ Numa investigação matemática, parte-se de uma questão aberta ou de um conjunto de informações pouco estruturadas a partir das quais se procura formular uma questão mais precisa e sobre ela produzir algumas conjecturas. Depois, testam-se essas conjecturas, sendo que algumas, por meio de contraexemplos, podem ser abandonadas. Outras, sem se revelarem inteiramente corretas, poderão ser aperfeiçoadas. Neste processo, por vezes formulam-se novas questões e abandonam-se, em parte ou no todo, as questões iniciais. As conjecturas que resistirem a vários testes vão ganhando credibilidade, estimulando a realização de uma prova que, se for conseguida, lhes conferirá validade matemática (PONTE, 2003). 
Podemos evidenciar, a partir dessas falas, que os licenciandos perceberam o potencial das atividades, bem como, já consideraram seu uso na sala de aula com seus alunos (ou futuros alunos). Nesse sentido, acreditamos que a proposta apresentada na disciplina, de utilizar recursos tecnológicos para desenvolver atividades investigativas, possibilitou que os alunos conhecessem um recurso tecnológico, assim como uma metodologia para utilizá-lo, ainda que as atividades foram apenas apresentadas a eles, por meio da leitura do texto e das propostas do professor.

Dessa forma, percebemos que a proposta apresentada aos licenciandos, também pôde proporcionar que eles identificassem possibilidades de integrar as tecnologias digitais em situações de ensino e aprendizagem e de enquadrá-las num novo paradigma do conhecimento e da aprendizagem (PONTE et al. 2003). Isso porque, considerando que as atividades investigativas podem ser vistas como situações de ensino e aprendizagem e, além disso, serem caracterizados por um diferenciado paradigma do conhecimento e da aprendizagem, a proposta de integrar as tecnologias digitais nessas atividades contribuiu para que os licenciandos identificassem essas possibilidades.

Finalizando as atividades da disciplina, o professor propôs a criação de um blog, a fim de que os licenciandos conhecessem uma forma para disponibilizar os materiais construídos, bem como compartilhar as experiências. Assim, cada licenciando construiu um blog individual, no qual disponibilizou todas as atividades realizadas ao longo da disciplina. Para isso, do mesmo modo como na criação dos podcast e screencast, os alunos apresentaram algumas dificuldades técnicas, produzindo diversos conhecimentos técnicos para o desenvolvimento da atividade.

Além disso, considerando que um documento pode ser visto como qualquer registro de informação e o blog tem também essa função, de registrar uma informação e compartilhar ideias, podemos inferir que a produção do blog, durante a disciplina, possibilitou que o licenciando tivesse contato com a elaboração de um documento em formato digital. Para ilustrar, a figura 1 mostra a postagem do podcast no blog de um licenciando. 
18 Trigonometria

2013

posted in Trigonometric

Olá, para começar o blog escolhi o tema Trigonometria.

Nada melhor para inicial nosso caminho em busca do conhecimento do que nosso velho amigo triângulo retângulo.

Neste breve Podcast, tento explicar de forma clara e resumida o que é o triângulo retângulo, seus elementos e as principais razōes trigonométricas.

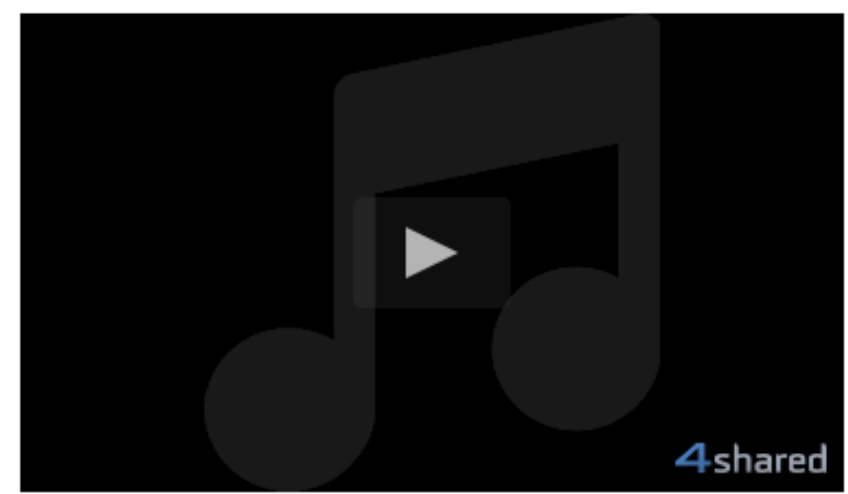

Espero que gostem, até à próxima.

Figura 1: Postagem no blog

Fonte: http://ninasilv.wordpress.com/

Enfim, podemos constatar que o desenvolvimento da disciplina possibilitou que os licenciandos produzissem conhecimentos relacionados ao uso das tecnologias digitais no ensino de Matemática, considerando propostas pedagógicas, como o uso dos recursos de áudio e vídeo e tarefas investigativas. Entendemos que não cabe a uma única disciplina produzir todos os conhecimentos relacionados ao uso das tecnologias, sendo que assim, outras possibilidades poderão ser exploradas ao longo do curso de licenciatura em Matemática.

\section{Considerações finais}

Acreditamos que o momento da formação inicial dos professores de Matemática é crucial para fortalecer o processo de integração das tecnologias digitais nas salas de aula. Diante disso, é incomensurável o valor de uma disciplina, como a que foi acompanhada, num curso de Licenciatura em Matemática, pois, além de corroborar as exigências legais, pode estar contribuindo para a prática docente do futuro professor, na medida em que os futuros professores puderam articular conhecimentos teóricos e 
práticos, além de discutirem sobre as possibilidades dessas tecnologias no contexto escolar.

O fato de a disciplina ser de um curso ofertado na modalidade de ensino a distância possibilita que os licenciandos tenham um contato constante com as tecnologias digitais, utilizando-as como meio de comunicação, interação e aprendizagem. Assim, embora a disciplina tenha um importante papel, entendemos que todo o curso poderá contribuir para que os licenciandos possam vir a utilizar as tecnologias digitais em suas aulas, ou seja, outras disciplinas do currículo poderão fornecer subsídios para isso ${ }^{9}$. Nesse sentido, concordamos com Schiller et al. (2011) que acreditam que o professor, formado na modalidade a distância, usando as tecnologias digitais tem a potencialidade de apropriar-se dessas inovações em sua prática docente de modo competente, crítico e criativo, visto que vivenciou o uso desses recursos para a própria produção de conhecimentos.

Além disso, sendo a disciplina acompanhada, uma disciplina de Prática de Ensino, acreditamos que as discussões dos textos, a produção dos recursos de áudio e vídeo e a discussões sobre as atividades investigativas, oportunizaram que a formação desses professores explorasse as tecnologias digitais de forma a identificar suas potencialidades. Almeida (2007) defende essa oportunidade na formação do professor e acrescenta que é preciso que "ele [o professor] participe de processos de formação que englobam dimensões tecnológicas, pedagógicas e teórico-metodológica" (ALMEIDA, 2007, p. 10). A partir das atividades desenvolvidas ao longo da disciplina, acreditamos que a mesma propiciou que tais dimensões fossem abrangidas.

Nesse sentido, podemos inferir que a disciplina acompanhada propiciou aos licenciandos tanto a produção de conhecimentos tecnológicos, que envolve, por exemplo, o desenvolvimento de habilidades para operar determinadas tecnologias digitais, quanto a produção de conhecimento tecnológico pedagógico, que é o saber da existência de diversos componentes e recursos tecnológicos e, como eles podem ser utilizados nos processos de ensino e aprendizagem (KOEHLER; MISHRA, 2005).

Por fim, acreditamos que a disciplina observada promoveu o desenvolvimento de competências e conhecimentos relacionados ao uso de tecnologias digitais nos processos de ensino e aprendizagem da matemática, além de proporcionar reflexões e

\footnotetext{
${ }^{9}$ Entendemos que isso não é prioridade da modalidade de ensino a distância. Num curso presencial também não cabe a uma única disciplina atender a demanda de conhecimentos para o uso das TIC, mas estamos entendendo aqui, que a modalidade a distância pode facilitar esse processo de produção de conhecimentos.
} 
debates sobre o papel de tais tecnologias na Educação Básica, convergindo com os pressupostos da legislação em vigor e contribuindo para a formação do futuro professor de matemática. Para nós, disciplinas dessa natureza, que promovem discussões, reflexões e vivências acerca das tecnologias digitais nos processos de ensino e aprendizagem, podem ser um caminho para que tais tecnologias cheguem, de fato, às aulas de Matemática.

\section{Referências}

ALMEIDA, M. E. B. Tecnologias Digitais na Educação: O futuro é hoje. In: E-TIC, $5^{\circ}$ ENCONTRO DE EDUCAÇÃO E TECNOLOGIAS DA INFORMAÇÃO E COMUNICAÇÃO, 2007, Rio de Janeiro. Anais... Rio de Janeiro, 2007. Online.

BASTOS, M.H.C. Do quadro-negro à lousa digital: a história de um dispositivo escolar. Cadernos de História da Educação. n.4, p.133-141, dez./jan. 2005.

BORBA, M. C. O computador é a solução, mas qual é o problema? In: SEVERINO, A. J.; FAZENDA, I. C. A. (Org.) Formação Docente: Rupturas e Possibilidades. Campinas: Papirus, 2002. p.141-161.

BRASIL. Conselho Nacional de Educação. Conselho Pleno. Resolução CNE/CP $N^{o} 01$, de 18 de fevereiro de 2002. Institui Diretrizes Curriculares Nacionais para a Formação de Professores da Educação Básica, em nível superior, curso de licenciatura, de graduação plena (2002).

BRASIL. Diretrizes Curriculares Nacionais para os Cursos de Matemática. Parecer CNE/CES 1.302/2001, 6 de Novembro de 2001.

BRASIL. Secretaria da Educação Fundamental. Parâmetros Curriculares Nacionais: matemática / Secretaria de Educação. Educação Fundamental. Brasília: MEC/SEF, 1998.

BOVO, A. A. Formação Continuada de Professores de Matemática para o Uso de Informática na Escola: Tensões entre propostas e implementação. Dissertação de mestrado - Universidade Estadual Paulista "Júlio de Mesquita Filho", Rio Claro, 2004.

COSTA, F. A.; RODRIGUEZ, C.; CRUZ, E.; FRADÃO, S. Repensar as TIC na Educação: O professor como agente transformador. Lisboa: Santillana, 2012.

D’AMBrosio, U. Prefácio. In: BORBA, M. C.; ARAÚJO, J. L. (Org.). Pesquisa Qualitativa em Educação Matemática. Belo Horizonte: Autêntica, 2004. p. 11-22.

GOLDENBERG, M. A Arte de Pesquisar: como fazer pesquisa qualitativa em Ciências Sociais. Rio de Janeiro: Record, 2003. 
KOEHLER, M. J.; MISHRA, P. Teachers Learning Technology by Design. Journal of Computing in Teacher Education, v. 21, n. 3, p. 94-102, 2005.

MALTEMPI, M. V.; MALHEIROS, A. P. S. Online distance mathematics education in Brazil: research, practice and policy. ZDM. Zentralblatt für Didaktik der Mathematik, v. 42, p. 291-303, 2010.

MENDES, A. TIC - Muita gente está comentando, mas você sabe o que é? 2008. Disponível em: <http://imasters.com.br/artigo/8278/> Último acesso em: 14 jun. 2015.

PERRENOUD, P. Dez novas competências para ensinar. Porto Alegre: Artes Médicas Sul, 2000.

PONTE, J. P. Investigar, ensinar e aprender. Actas do ProfMat 2003 (CD-ROM, pp. 2539). Lisboa: APM, 2003a.

PONTE, J. P. Investigação sobre investigações matemáticas em Portugal. Investigar em Educação, v. 2, p. 93-169, 2003b.

PONTE, J. P.; OLIVEIRA, H.; VARANDAS, J. M. O contributo das tecnologias de informação e comunicação para o desenvolvimento do conhecimento e da identidade profissional. In: FIORENTINI, D. (Org.), Formação de professores de Matemática: Explorando novos caminhos com outros olhares. Campinas, SP: Mercado de Letras, 2003. p. 159-192.

SANTOS, K. E. S.; BRITO, A. de J. Discursos sobre Trabalho no Cenário de Formação de Professores: Um olhar para as legislações. VIDYA, v. 31, n. 2, p. 55-68, jul./dez. 2011.

SCHILLER, J.; LAPA, A. B.; CERNY, R. Z. Ensinar com as Tecnologias de Informação e Comunicação: Retratos da docência. Revista e-curriculum, São Paulo, v.7 n.1, p. 2-19, abr. 2011.

UFOP. Universidade Federal de Ouro Preto. Centro de Educação Aberta e Distância. Curso de Matemática a distância. 2009. Disponível em: <http://www.cead.ufop.br/images/stories/arquivos/matrizmatematica03_2009v2.pdf> Último acesso em: 14 jun. 15.

ZABEL, M. Luz, Câmera, Flashs: Uma compreensão sobre a disciplina de Prática de Ensino de Matemática a Distância. 2014. 153 f. Dissertação mestrado - Universidade Estadual Paulista "Júlio de Mesquita Filho", Rio Claro, 2014. 
MARÍLIA ZABEL. Licenciada em Matemática pela Universidade do Estado de Santa Catarina e mestre em Educação Matemática pela Universidade Estadual Paulista "Júlio de Mesquita Filho", campus de Rio Claro. Membro do Grupo de Pesquisa em Informática, outras Mídias e Educação Matemática (GPIMEM). Atualmente é docente da rede estadual de ensino de Santa Catarina.

ANA PAULA DOS SANTOS MALHEIROS. Licenciada em Matemática pela Universidade Estadual Paulista "Júlio de Mesquita Filho", campus de Rio Claro, mestre e doutora em Educação Matemática pela mesma instituição. Docente da Universidade Estadual Paulista "Júlio de Mesquita Filho", campus de São José do Rio Preto e do Programa de Pós-Graduação em Educação Matemática. Pesquisadora associada do Grupo de pesquisa em Informática, outras Mídias e Educação Matemática (GPIMEM).

Recebido: 16 de dezembro de 2014

Revisado: 14 de março de 2015

Aceito: 19 de maio de 2015 